\title{
Frontal facial proportions of 12-year-old southern Chinese: a photogrammetric study
}

\author{
Charles Yat Cheong Yeung ${ }^{1}$, Colman Patrick McGrath², Ricky Wing Kit Wong ${ }^{3}$, Erik Urban Oskar Hägg ${ }^{4}$, \\ John LO ${ }^{5}$ and Yanqi Yang ${ }^{6^{*}}$
}

\begin{abstract}
This study aimed to establish norm values for facial proportion indices among 12-year-old southern Chinese children, to determine lower facial proportion, and to identify gender differences in facial proportions.

A random population sample of 514 children was recruited. Fifteen facial landmarks were plotted with ImageJ (V1.45) on standardized photos and 22 Facial proportion index values were obtained. Gender differences were analyzed by 2-sample t-test with $95 \%$ confidence interval. Repeated measurements were conducted on approximately $10 \%$ of the cases. The rate of adopted subjects was $52.5 \%$ (270/514). Intraclass correlation coefficient values (ICC) for intra- examiner reliability were $>0.87$. Population facial proportion index values were derived. Gender differences in 11 of the facial proportion indices were evident $(P<0.05)$.

Upper face-face height (N-Sto/ N- Gn), vermilion height (Ls-Sto/Sto-Li), upper face height-biocular width (N-Sto/ExR-ExL) and nose -face height ( $\mathrm{N}-\mathrm{Sn} / \mathrm{N}-\mathrm{Gn})$ indices were found to be larger among girls $(P<0.01)$. Males had larger lower faceface height ( $S n-G n / N-G n$ ), mandibulo-face height (Sto-Gn/N-Gn), mandibulo-upper face height (Sto-Gn/N-Sto), nasal (AIR-AlL/N-Sn), upper lip height-mouth width (Sn-Sto/ChR-ChL), upper lip-upper face height (Sn-Sto/N-Sto) and upper lip-nose height (Sn-Sto/N-Sn) indices $(P<0.05)$.

Population norm of facial proportion indices for 12-year-old Southern Chinese were derived and mean lower facial proportion were obtained. Sexual dimorphism is apparent.
\end{abstract}

Keywords: Facial proportions, Southern Chinese, Photogrammetry, Population norm, Facial attractiveness, Diagnosis, Treatment outcome evaluation, Orthodontics, Orthognathic surgery, Plastic surgery, Cosmetic surgery

\section{Introduction}

Facial attractiveness has been a subject of interest since the beginning of recorded history. Bashour reviewed the historical and current literatures and concluded with four important cues that emerge as being the most important determinants of facial attractiveness [1]. They are: (i) averageness, (ii) sexual dimorphism, (iii) youthfulness, and (iv) symmetry. Averageness is regarded as one of the most important factors and supported by various studies [2-6].

Facial attractiveness has long been of central concern to orthodontic and surgical care given that treatments are capable of changing facial appearance and thereby improve

\footnotetext{
* Correspondence: yangyanq@hku.hk

${ }^{6}$ Department of Paediatric Dentistry and Orthodontics, Faculty of Dentistry,

The University of Hong Kong, Hong Kong SAR, China

Full list of author information is available at the end of the article
}

facial attractiveness [7]. It is therefore important to establish population norms to address the averageness cue, and provide insight on sexual dimorphism and youthfulness. Symmetry can be assessed clinically without the need of a norm.

Farkas suggested the use of facial proportion indices to assess aesthetics relating to facial proportions in different facial types [8]. Edler quantified facial attractiveness after orthognathic surgery and found, the greater the improvement in facial proportion indices, the better the aesthetic result as judged by orthodontists and maxillofacial surgeons [6]. These post surgical indices correlated closely to Farkas' findings. Facial proportion is, therefore, important in both clinical diagnosis and treatment outcome evaluation.

Photogrammetry is increasingly being employed to assess facial characteristics $[6,9-14]$. It is reported to be 
valid for many measurements $[15,16]$, reliable $[6,10-13$, $16,17]$ and is a practical approach to clinical analyses and comparison [6, 14, 17].

While facial proportion norms are well-established for Caucasian populations [9], it remains paucity for southern Chinese.

The aims of this study were:

I. To provide a database of norm of facial proportion indices for 12-year-old southern Chinese for surgical and orthodontic diagnosis.

II. To determine sexual dimorphism in facial proportions.

III.To determine the lower facial proportion

\section{Materials and method \\ Sample}

This epidemiological study was conducted in Hong Kong SAR, China among 12-year-old children. Ethical approval was obtained by the local IRB committee (UW 09-453). Ten percent of all secondary schools in Hong Kong SAR were randomly selected and children within each selected school were invited to participate. Written informed consent was obtained from parents and children provided their ascent. A sample of 514 (259 males, 255 females) 12-year-old children was recruited. That was approximately $10 \%$ of the Chinese birth cohort since all 12-year-old children in Hong Kong, spread over all secondary schools, are included in the cohort.

\section{Photographic set up}

A scale backdrop of $1 \mathrm{~cm}$ increments with a plumbline was set up for a camera-subject distance of around $170 \mathrm{~cm}$. The camera used was Canon EOS 400D (Canon, Shimomaruko, Ohta-ku, Tokyo, Japan) with Canon EF-S $60 \mathrm{~mm} \mathrm{f} / 2.8$ Macro USM Lens and Canon MR-14EX TTL Macro Ring Lite Flash. Subjects were first instructed to a stand with their eyes looking forward to a vertically standing mirror on the side for a natural head posture and then turn their whole body $90^{\circ}$ to face the camera with the lip relax. Glasses or other accessories which may obstruct the face were taken away beforehand. The photo was then taken in natural head posture [18].

\section{Selection of landmarks and proportion indices: (Fig. 1)}

Fifteen landmarks (Fig. 1) as employed by Farkas and Munro [8] were considered; based on key variables considered by Bishara [10-12] (1) visibility in most frontal photographs (2) reliable identification (3) minimally affected by the subject's grooming, and (4) involved in the measurement of proportional indices of interest. Twenty-two proportion indices (Table 1) employed by Farkas and Munro [8] were selected to be investigated basing on key variables considered by Bishara [10-12],

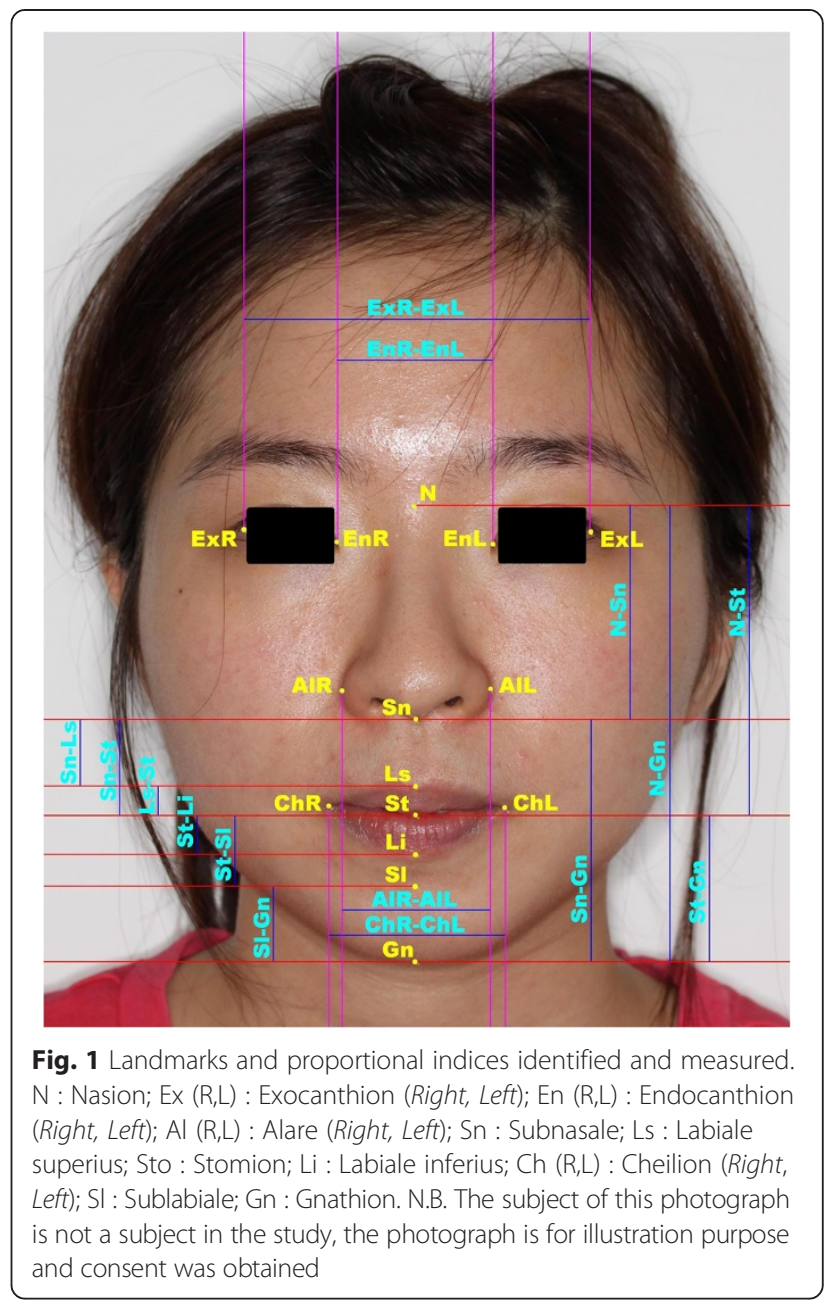

and Edler [6] (1) Measurable on a frontal photographs; (2) reliability; and (3) be potentially changed by the effects of orthodontics and/or orthognathic surgery.

\section{Selection of photos}

Photos were inspected for their quality and usability in identification of landmarks and validity in measurement of the proportion indices. Photos were excluded if: (1) landmarks were obscured; (2) head tilted up or down significantly; (3) head turned left or right by assessing symmetrical structures; (4) out focused photo; (5) subject wearing glasses; (6) subject showing lip strain or obviously opened mouth; (7) subject smiled; (8) patient partly or completely closed their eyes; and (9) subject previously or currently having orthodontic treatment.

\section{Digitalization of photos}

The selected photos were cropped to show the head only. A tangent at superior palpebral sulci was used to determine the vertical level of Nasion $[8,19]$. Landmarks were located with ImageJ (V.1.45) (USA National Institutes of Health) and position of each landmark was recorded as 
Table 1 Descriptions of Facial Proportion Indices abd their respective intraclass correlation coefficients of intra examiner reliability

\begin{tabular}{|c|c|c|}
\hline Index & Description & $\begin{array}{l}\text { Intra-examiner } \\
\text { reliability (ICC) } \\
\end{array}$ \\
\hline Upper face-face height index & N-Sto/ N- Gn ×100 & 1 \\
\hline Lower face-face height index & $S n-G n / N-G n \times 100$ & 0.99 \\
\hline Mandibulo-face height index & Sto-Gn/N-Gn ×100 & 1 \\
\hline $\begin{array}{l}\text { Mandibulo-upper face } \\
\text { height index }\end{array}$ & Sto-Gn/N-Sto $\times 100$ & 1 \\
\hline $\begin{array}{l}\text { Mandibulo-lower face } \\
\text { height index }\end{array}$ & Sto-Gn/Sn-Gn ×100 & 0.99 \\
\hline Nasal index & AlR-AlL/N-Sn $\times 100$ & 0.88 \\
\hline $\begin{array}{l}\text { Upper lip height-mouth } \\
\text { width index }\end{array}$ & Sn-Sto/ChR-ChL ×100 & 0.98 \\
\hline $\begin{array}{l}\text { Cutaneous-total upper lip } \\
\text { height index }\end{array}$ & Sn-Ls/Sn-Sto $\times 100$ & 0.95 \\
\hline $\begin{array}{l}\text { Vermilion-total upper lip } \\
\text { height index }\end{array}$ & Ls-Sto/Sn-Sto $\times 100$ & 0.95 \\
\hline $\begin{array}{l}\text { Vermilion-cutaneous upper lip } \\
\text { height index }\end{array}$ & Ls-Sto/Sn-Ls ×100 & 0.95 \\
\hline Vermilion height index & Ls-Sto/Sto-Li ×100 & 0.96 \\
\hline Chin-mandible height index & SI-Gn/Sto-Gn ×100 & 0.9 \\
\hline $\begin{array}{l}\text { Upper face height-biocular } \\
\text { width index }\end{array}$ & N-Sto/ExR-ExL ×100 & 0.99 \\
\hline Intercanthal-nasal width index & EnR-EnL/AIR-AlL ×100 & 0.99 \\
\hline Nose-face height index & N-Sn/N-Gn ×100 & 0.99 \\
\hline Nose-mouth width index & AIR-AIL/ChR-ChL ×100 & 0.98 \\
\hline $\begin{array}{l}\text { Upper lip-upper face } \\
\text { height index }\end{array}$ & Sn-Sto/N-Sto $\times 100$ & 0.98 \\
\hline $\begin{array}{l}\text { Upper lip-mandible } \\
\text { height index }\end{array}$ & Sn-Sto/Sto-Gn $\times 100$ & 0.99 \\
\hline Upper lip-nose height index & Sn-Sto/N-Sn $\times 100$ & 0.97 \\
\hline Lower lip-face height index & Sto-SI/Sn-Gn ×100 & 0.89 \\
\hline $\begin{array}{l}\text { Lower lip-mandible } \\
\text { height index }\end{array}$ & Sto-SI/Sto-Gn ×100 & 0.9 \\
\hline Lower lip-chin height index & Sto-SI/SI-Gn $\times 100$ & 0.91 \\
\hline
\end{tabular}

a set of X-Y pixel coordinates by the same trained operator. The proportion indices were generated by Microsoft Excel ${ }^{\circ}$ with the formulas in Table 1.

\section{Statistical analysis}

For each facial proportion index, descriptive statistics of mean, standard deviation and range (maximum, minimum) were generated by Statistical Product and Service Solutions (V20) (IBM Corporation, New York, USA). Two sample T- test (with $95 \%$ confidence interval provided) were used to identify any gender difference. The intraclass correlation coefficients [20] were calculated by SPSS (V.19) to assess for intra-examiner reliability, among approximately $10 \%$ of randomly selected subjects that were re-analyzed and compared to original assessments.

\section{Results}

Out of 514 subjects, $53 \%$ (270) were included in the analysis, among that, $51 \%$ (137) were female. $47 \%$ (244) were excluded according to the exclusion criteria (as described above). Intra-examiner reliability is presented in Table 1. The intraclass correlation coefficients were all above 0.87 for intra examiner reliability, indicating very good/excellent reliability [20].

Facial proportion index norm values are presented in Table 2. Greatest variance were observed in vermilion cutaneous-upper lip height (Males: 29.58-145.59, Females: 28.81-124.32), vermilion height (Males: 55.26-120.75, Females: 44.59-175.00) and lower lip-chin height (Males: 36.25-135.63, Females: 25.44-131.40) indices. Lowest variances were observed in upper face-face height (Males: 56.73-70.79, Females: 58.35-70.19), lower face-face height (Males: 50.34-62.69, Females: 48.06-60.95) and mandibulo-lower face height (Males: 57.98-72.07, Females: 58.64-70.64) indices. From lower face-face height index, the proportion of lower face was $56 \%$ of total face height. The proportion of upper lip height (Sn-Sto), lower lip height (Sto-Sl) and chin height (Sl-Gn) were found to be $35.12,27.33$ and $37.55 \%$ respectively.

Gender differences in 11 of the 22 facial proportion indices assessments were apparent. For females, upper face-face height $(P<0.05)$, vermilion height $(P<0.001)$, upper face height-biocular width $(P<0.01)$ and nose -face height $(P<0.001)$ indices were larger. In contrast, lower face-face height $(P<0.001)$ mandibulo-face height $(P<0.05)$, mandibulo-upper face height $(P<0.05)$, nasal $(P<0.001)$, upper lip height-mouth width $(P=0.001)$, upper lip-upper face height $(P<0.001)$ and upper lipnose height $(P<0.001)$ indices were larger in males. The index with the largest mean percentage difference (7.56 \%) between genders was upper lip-nose height index.

\section{Discussion}

This study was conducted on a random population sample of 12-year-old children, as opposed to small, non-random, convenient samples as described in the majority of photogrammetric studies published to date [21-23]. With the rate of adopted subjects of $53 \%$, there are a number of factors to account for the loss of samples including less than ideal cooperation from 12 years old children, time constraint and past or current orthodontic treatment. This reflects the difficulties in performing population-wide photogrammetric studies under non-clinical/outreach settings in the community. Nevertheless, the sample size was sufficient to provide populations norms and to discover gender differences and it is one of the largest samples for photogrammetric study with random population 
Table 2 Mean, standard deviation, maximum, minimum and p-values of statistical tests (2 sample t-test) of facial proportion indices

\begin{tabular}{|c|c|c|c|c|c|c|c|c|c|}
\hline & \multicolumn{4}{|c|}{ Male $(n=133)$} & \multicolumn{4}{|c|}{ Female $(n=137)$} & \multirow[b]{2}{*}{$P$-value } \\
\hline & Mean & SD & Min. & Max. & Mean & SD & Min. & Max. & \\
\hline Upper face-face height index & 63.27 & 2.58 & 56.73 & 70.79 & 63.92 & 2.36 & 58.35 & 70.19 & $0.031^{*}$ \\
\hline Lower face-face height index & 56.75 & 2.44 & 50.34 & 62.69 & 55.25 & 2.59 & 48.06 & 60.95 & $0.000^{* * *}$ \\
\hline Mandibulo-face height index & 36.73 & 2.58 & 29.21 & 43.27 & 36.08 & 2.36 & 29.81 & 41.65 & $0.031^{*}$ \\
\hline Mandibulo-upper face height index & 58.33 & 6.54 & 41.25 & 76.26 & 56.66 & 5.80 & 42.47 & 71.37 & $0.028^{*}$ \\
\hline Mandibulo-lower face height index & 64.69 & 2.83 & 57.98 & 72.07 & 65.29 & 2.63 & 58.64 & 70.64 & 0.075 \\
\hline Nasal index & 77.12 & 5.69 & 64.32 & 93.83 & 73.99 & 6.54 & 60.70 & 93.94 & $0.000^{* * *}$ \\
\hline Upper lip height-mouth width index & 52.02 & 6.47 & 37.09 & 71.21 & 49.36 & 6.21 & 36.46 & 67.05 & $0.001^{* *}$ \\
\hline Cutaneous-total upper lip height index & 62.16 & 6.84 & 40.72 & 77.17 & 61.99 & 6.82 & 44.58 & 77.63 & 0.838 \\
\hline Vermilion-total upper lip height index & 37.84 & 6.84 & 22.83 & 59.28 & 38.01 & 6.82 & 22.37 & 55.42 & 0.837 \\
\hline Vermilion-cutaneous upper lip height index & 63.00 & 19.83 & 29.58 & 145.59 & 63.30 & 18.37 & 28.81 & 124.32 & 0.898 \\
\hline Vermilion height index & 76.61 & 12.08 & 55.26 & 120.75 & 82.21 & 19.80 & 44.59 & 175.00 & $0.005^{* *}$ \\
\hline Chin-mandible height index & 58.12 & 5.57 & 42.44 & 73.39 & 58.78 & 6.03 & 43.22 & 79.72 & 0.352 \\
\hline Upper face height-biocular width index & 85.33 & 5.01 & 73.41 & 98.37 & 86.92 & 4.54 & 74.69 & 98.24 & $0.007^{* *}$ \\
\hline Intercanthal-nasal width index & 95.22 & 6.70 & 79.48 & 112.82 & 95.37 & 7.75 & 77.32 & 113.96 & 0.871 \\
\hline Nose -face height index & 43.25 & 2.44 & 37.31 & 49.66 & 44.75 & 2.59 & 39.05 & 51.94 & $0.000^{* * *}$ \\
\hline Nose-mouth width index & 86.22 & 7.03 & 68.69 & 109.87 & 84.70 & 7.02 & 70.98 & 109.49 & 0.075 \\
\hline Upper lip-upper face height index & 31.65 & 2.31 & 25.60 & 37.19 & 30.02 & 2.55 & 24.28 & 35.99 & $0.000^{* * *}$ \\
\hline Upper lip-mandible height index & 54.87 & 6.76 & 38.75 & 72.48 & 53.42 & 6.22 & 41.57 & 70.55 & 0.067 \\
\hline Upper lip-nose height index & 46.46 & 4.96 & 34.41 & 59.21 & 43.08 & 5.26 & 32.07 & 56.23 & $0.000^{* * *}$ \\
\hline Lower lip-face height index & 27.05 & 3.43 & 17.07 & 35.81 & 26.87 & 3.80 & 12.91 & 36.22 & 0.693 \\
\hline Lower lip-mandible height index & 41.88 & 5.57 & 26.61 & 57.56 & 41.22 & 6.03 & 20.28 & 56.79 & 0.352 \\
\hline Lower lip-chin height index & 73.66 & 17.05 & 36.25 & 135.63 & 71.94 & 18.03 & 25.44 & 131.40 & 0.421 \\
\hline
\end{tabular}

${ }^{* P}$-value $<0.05,{ }^{* *}$ P-value $<0.01,{ }^{* * *}$-value $<0.001$

sample and largest range of assessment of proportion indices.

A smaller local study analyzed facial profiles with photogrammetry on only 8212 -year-old southern Chinese with just five proportion indices [21]. Findings were consistent with the present study, with mean differences less than 1 standard deviation for four indices: lower-face-face height index, mandibulo-lower face height, intercanthal-nasal width and lower lip-face height indices. The only inconsistency was reported for the lower lip-face height index, which they reported a statistically significant gender difference. In comparison with northern America Caucasian population [8], the only index that differed by more than 2 standard deviation is the nose-mouth width index for both males and females. This indicates that southern Chinese have a relatively wider nose (AlR-AlL) or narrower mouth (ChR-ChL) compared to Caucasians. The nasal index for males, upper face height-biocular width index and upper-lip-mandible height index for females were larger in southern Chinese by almost 2 standard deviations. The reverse was found for the female mandibuloupper face height index.
Of a particular importance to orthodontics and orthognathic surgery is the lower face proportion. The lower face height in our study was found to be $56.7 \%$ (male) and $55.3 \%$ (female) of the total face height corresponding well to lateral cephalometric study [24] (M:56.5\%, F:55.7 \%), photogrammetric study [25] in Nigerian adults (M:58.15 \%, F:56.97 \%) and anthropotmetric study [8] on 12-year-old Caucasian children (M:59.7 \%, F:59.5 \%). Regarding the proportions of the lower third of the face, Renaissance artist Francesca [8] suggested that the lower lip and chin should make up two thirds of the lower one third of face and lower lip and chin should have the same proportion, this is widely adopted in orthodontics and surgery text. Farkas had found proportionality from anthropometric study [8], which is 31.2, 26.2 and $42.6 \%$ for Sn-Sto, Sto-Sl and Sl-Gn. In our study, the proportion was 35.1, 27.3 and $37.6 \%$ respectively.

Farkas [8], Song [26] and Bao [27] reported that there gender difference in facial dimension and proportions but the average differences were small. The results from this study generally supports Farkas' conclusion. In this study, 
11 (50\%) out of 22 facial proportion indices showed significant gender differences. All except 4 of the indices had a percentage difference of less than $5 \%$. They are upper lip-nose height $(7.6 \%)$, vermilion height $(7.0 \%)$, upper lip-upper face height (5.3\%) and upper lip height-mouth width (5.3\%) indices.

The norm facial proportion indices obtained can be used for clinical assessment and comparison with same analysis and photogrammetric technique. Frontal photogrammetry was widely used to assess treatment change [6, 9-12], attractiveness [13, 28, 29], comparisons between different ethnic groups $[13,14,30]$ and growth $[10-12,31]$ in additional to daily use for clinical diagnosis and treatment planning.

To conclude, the following were the key findings of this study.

I. Population norm of facial proportion indices are obtained from the mean values of this study and can serve as a reference to evaluate facial proportions in treatment planning and treatment outcome assessment using the same frontal photogrammetric analysis.

II. Gender differences in facial proportion were found in 11 indices. Lower face-face height index, mandibulo-face height index, mandibulo-upper face height index, nasal index, upper lip height-mouth width index, upper lip-upper face height index and upper lip-nose height index were significantly larger in males. The findings were opposite for upper faceface height index, vermilion-height index, upper face height-biocular width index and nose -face height index.

III. The lower face height is found to be $56.7 \%$ (male) and $55.3 \%$ (female) of the total face height and proportions of lower facial height were 35.1, 27.3 and $37.6 \%$ for Sn-Sto, Sto-Sl and Sl-Gn respectively.

IV.Ethnic differences were evaluated by comparing with a North American Caucasian population, southern Chinese was found to have a relatively wider nose (AlR-AlL) or narrower mouth (ChR-ChL) compared to the Whites.

\section{Competing interests}

The authors declare that they have no competing interests.

\section{Authors' contributions}

CY did all the measurements, calculations and drafted the manuscript. CM designed the study and amended the manuscript. RW helped with the arrangement of the survey and the manpower associated. UH set objectives for the study, calibrated the examiner and revised the manuscript. JL advised on the methodology and helped with data analysis. YY organized the survey, designed the study, helped with data analysis and revised the manuscript. All authors read and approved the final manuscript.

\section{Acknowledgment}

I would like to thank Mr Shadow Yeung for his technical and statistical support, Miss Angela for the permission of use of her frontal photo, Miss
Karen Lau for editing and to all who have collaborated in any respects of this research project.

\section{Author details}

${ }^{1}$ Department of Paediatric Dentistry and Orthodontics, Faculty of Dentistry, The University of Hong Kong, Hong Kong SAR, China. ${ }^{2}$ Department of Periodontology and Public Health, Faculty of Dentistry, The University of Hong Kong, Hong Kong SAR, China. ${ }^{3}$ Department of Paediatric Dentistry and Orthodontics, Faculty of Dentistry, The University of Hong Kong, Hong Kong SAR, China. ${ }^{4}$ Department of Paediatric Dentistry and Orthodontics, Faculty of Dentistry, The University of Hong Kong, Hong Kong SAR, China. ${ }^{5}$ Department of Oral and Maxillofacial Surgery, Faculty of Dentistry, The University of Hong Kong, Hong Kong SAR, China. ' Department of Paediatric Dentistry and Orthodontics, Faculty of Dentistry, The University of Hong Kong, Hong Kong SAR, China.

Received: 13 March 2015 Accepted: 29 July 2015

Published online: 14 August 2015

\section{References}

1. Bashour M. History and current concepts in the analysis of facial attractiveness. Plast Reconstr Surg. 2006;118(3):741-56.

2. Symons D. The evolution of human sexuality. 1st ed. New York: Oxford University Press; 1979.

3. Langlois JH, Roggman LA. Attractive faces are only average. Psychol Sci. 1990;1:115-21.

4. Strzalko J, Kaszycka KA. Physical attractiveness: interpersonal and intrapersonal variability of assessments. Soc Biol. 1991;39:170-6.

5. Grammer K, Thornhill R. Human facial attractiveness and sexual selection: the role of symmetry and averageness. J Comp Psychol. 1994;108:233-42.

6. Edler R, Agarwai P, Wertheim D, Greenhill D. The use of anthropometric proportion indices in the measurement of facial attractiveness. Eur J Orthod. 2006:28(3):274-81.

7. Mackley RJ. An evaluation of smiles before and after orthodontic treatment. Angle Orthod. 1993;63:183-9.

8. Farkas LG, Munro IR. Anthropometric facial proportions in medicine. 1st ed. Springfield: Thomas; 1987.

9. Gode S, Tiris FS, Akyildiz S, Apaydin F. Photogrammetric analysis of soft tissue facial profile in Turkish Rhinoplasty population. Aesthetic Plast Surg. 2011;35:1016-21.

10. Bishara SE, Jorgensen GJ, Jakobsen JR. Changes in facial dimensions assessed from lateral and frontal photographs. Part I-Methodology. Am J Orthod Dentofacial Orthop. 1995;108:389-93.

11. Bishara SE, Jorgensen GJ, Jakobsen JR. Changes in facial dimensions assessed from lateral and frontal photographs. Part II-Results and conclusions. Am J Orthod Dentofacial Orthop. 1995;108:489-99.

12. Bishara SE, Cummins DM, Jakobsen JR. "A computer assisted photogrammetric analysis tissue changes after orthodontic treatment. Part II: Results. Am J Orthod Dentofacial Orthop. 1995;108:38-47.

13. Rhee SC, Dhong ES, Yoon ES. Photogrammetric facial analysis of attractive Korean entertainers. Aesthetic Plast Surg. 2009;33:167-74.

14. Sim RS, Smith JD, Chan AS. Comparison of the aesthetic facial proportions of Southern Chinese and White women. Arch Facial Plast Surg. 2000;2:113-20.

15. Farkas LG, Bryson W, Klotz J. Is photogrammetry of face reliable? Plast Reconstr Surg. 1980;66:346-55.

16. Guyot L, Dubuc M, Richard O, Philip N, Dutour O. Comparison between direct clinical and digital photogrammetric measurements in patients with 22q11 microdeletion. Int J Oral Maxillofac Surg. 2003;32:246-52.

17. Muradin MSM, Rosenberg A, Bilt AV, Stoelinga JW, Koole R. The reliability of frontal facial photographs to assess changes in nasolabial soft tissues. Int J Oral Maxillofac Surg. 2007;36:728-34.

18. Cooke MS, Wei SH. The reproducibility of natural head posture: a methodological study. Am J Orthod Dentofacial Orthop. 1988;93:280-8.

19. Ashley-Montagu MF. The location of the nasion in the living. Am J Phys Anthropol. 1935;20:81-95.

20. Stanish WM, Taylor N. Estimation of the intraclass correlation coefficient for the analysis of covariance model. Am Stat. 1983;37:221-4.

21. Yuen SW, Hiranaka DK. A photographic study of the facial profiles of southern Chinese adolescents. Quintessence Int. 1989;20:665-76.

22. Porter JP. The average African American male face. Arch Facial Plast Surg. 2004;6:78-81. 
23. Sepehr A, Mathew PJ, Pepper JP, Karimi K, Devcic Z, Karam AM. The Persian Woman's face: a photogrammetric analysis. Aesthetic Plast Surg. 2012;36:687-91.

24. Saksena SS, Walker GE, Bixler D. A Clinical atlas Roentgencephalometry in norma lateralis. New York: Liss; 1987.

25. Loveday OE. Photogrammetric analysis of soft tissue profile of the face of igbos in port harcourt. Asian J Med Sci. 2011;3(6):228-33.

26. Song WC, Kim JI, Kim SH, Shin DH, Hu KS, Kim HJ, et al. Female-to-male proportion of head and face in Koreans. J Craniofac Surg. 2009;20:356-61.

27. Bao B, Yu S, Cai Y. The analysis of frontal facial soft tissue of normal native adult of Han race of Guangdong Province by using the computer assisted photogrammetric system. Hua Xi Kou Qiang Yi Xue Za Zhi. 1997;15(3):266-75

28. Kiekens RM, Kuijpers Jagtman AM, Van't Hof MA, Van't Hof BE, Straatman H, Maltha JC. Facial esthetics in adolescents and its relationship to "ideal" ratios and angles. Am J Orthod Dentofacial Orthop. 2008;133:188. 1-8.

29. Kiekens RM, Kuijpers-Jagtman AM, van't Hof MA, van't Hof BE, Maltha JC. Putative golden proportions as predictors of facial esthetics in adolescents. Am J Orthod Dentofacial Orthop. 2008;134:480-3.

30. Jeffries JM, DiBernardo B, Rauscher GE. Computer analysis of the AfricanAmerican face. Ann Plast Surg. 1995;34:318-22.

31. Ferring $\mathrm{V}$, Pancherz $\mathrm{H}$. Divine proportions in the growing face. Am J Orthod Dentofacial Orthop. 2008;134:472-9.

\section{Submit your next manuscript to BioMed Central and take full advantage of:}

- Convenient online submission

- Thorough peer review

- No space constraints or color figure charges

- Immediate publication on acceptance

- Inclusion in PubMed, CAS, Scopus and Google Scholar

- Research which is freely available for redistribution 